\title{
Energy Efficiency: an Opportunity for Research and Improvement
}

Luis Guerrero Gómez ${ }^{1}$

Montserrat Espín García ${ }^{2}$

\begin{abstract}
In this paper, Bureau Veritas explains the new international regulations on air pollution, its origin, and its position in the marine market to help and develop several technical solutions suitable to the world's fleet.

Key words: Energy efficiency, regulatory framework, energy efficiency design index, energy efficiency operational index, ship energy efficiency management plan.
\end{abstract}

\section{Resumen}

En este artículo, Bureau Veritas explica las nuevas reglamentaciones internacionales sobre contaminación del aire, así como sus orígenes y su posición en el mercado para ayudar y desarrollar diferentes soluciones técnicas aplicables a la flota mundial.

Palabras claves: Eficiencia energética, marco reglamentario, índice de eficiencia energética de diseño, índice de eficiencia operacional, plan de gestión de la eficiencia energética a bordo.

Date Received: - Fecha de recepción:

Date Accepted: - Fecha de aceptación:

\footnotetext{
${ }^{1}$ Bureau Veritas, Departamento Naval. Madrid, Espańa. e-mail: Luis.guerrero@es.bureauveritas.com

${ }^{2}$ Bureau Veritas, Departamento Maquinaría, Electricidad y Seguridad. Madrid, España. e-mail: montserrat.espin@es.bureauveritas.com
} 


\section{Introduction}

During the $20^{\text {th }}$ century, environmental awareness increased in our personal mindset and professional activity. A way to reduce environmental pollution is to improve energy efficiency in every aspect of our lives: household energy consumption, industrial energy consumption, and transport energy consumption. Given that in the current society energy mainly comes from the combustion of products containing carbon (fuels, coal, gases) and because this combustion produces substantial air pollution due to greenhouse gases, the concept of carbon footprint was developed. It is defined as the total greenhouse gases produced by direct or indirect effects from an individual, organization, event, or product.

Therefore, in accordance with the information and data published by the International Energy Agency (IEA), during 2010, the total $\mathrm{CO}_{2}$ emissions attributed to human origin were 30,276.1 million tons; this value is higher than the value of total emissions produced during 2009. Total $\mathrm{CO}_{2}$ emissions increased by $4.6 \%$. We must keep in mind that the total $\mathrm{CO}_{2}$ emissions value in 2009 was lower than in 2008 due to the financial crisis endured by western economies. Under normal conditions, the natural trend is a steady increase of $\mathrm{CO}_{2}$ emissions generation. Therefore, actions have to be taken to reduce $\mathrm{CO}_{2}$ emissions. Among other important data, published by IEA, the percentages of $\mathrm{CO}_{2}$ emissions by sectors must be accounted. Fig. 1. The percentage of $\mathrm{CO}_{2}$ emissions from the generation of electricity and heat is $41.2 \%$ (compared to $40.8 \%$ of emissions during 2009 in this sector), this being the most air pollutant activity, and followed very closely by the transport percentage of $\mathrm{CO}_{2}$ emissions during 2010 at $22.31 \%$ (20.8\% during 2009), and then followed by the manufacturing industries and construction activities (20.4\% of $\mathrm{CO}_{2}$ emissions during 2010) and the other sectors with a percentage of $\mathrm{CO}_{2}$ emissions of $16.69 \%$.

Focusing on the transport activity (Fig. 2.), most $\mathrm{CO}_{2}$ emissions are generated by road transport
(16.8\% of the total $\mathrm{CO}_{2}$ emissions and $73.6 \%$ of the $\mathrm{CO}_{2}$ emissions produced by the transport activity); meanwhile, only $2.13 \%$ of the total $\mathrm{CO}_{2}$ emissions are due to maritime transport $(9.5 \%$ of the $\mathrm{CO}_{2}$ emissions generated by the total transport activity). As estimated, $90 \%$ of the overall tons involved in the commercial activity are carried by ships. It implies that marine transport is the most efficient means of transport from the environmental point of view.

Fig. 1. Percentage of $\mathrm{CO}_{2}$ Emissions by Activities (2010)

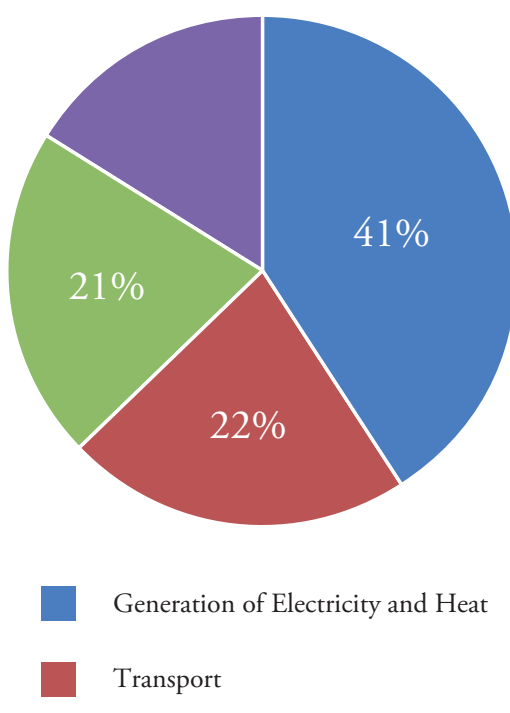

Fig. 2. Percentage of $\mathrm{CO}_{2}$ Emissions (transport sector, 2010)

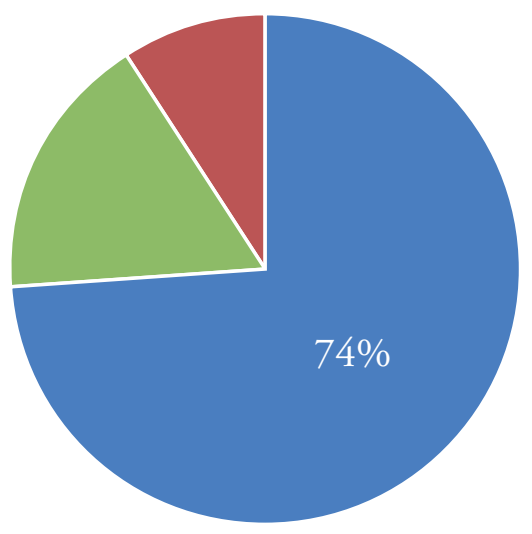

Road Transport $\quad$ Marine Transport

Other Transports (plane...) 


\section{Regulatory Framework}

Taking into consideration the previous data on air pollution due to $\mathrm{CO}_{2}$ emissions, and with marine transport being a "green transport" compared to other types of transport, additional efforts to control and slow down $\mathrm{CO}_{2}$ emissions must be requested.

Given that marine transport is a global commercial activity, international organizations have expressed high concern about air pollution. This has resulted in several international antipollution regulations; the latest regulations are focused on air pollution.

It has to be emphasized that all international regulations are enforced by the flag states. Therefore, if the flag states do not ratify the regulations and/or conventions, the vessels under that flag are not obligated to achieve the international regulations. In any case, the port authorities where the vessels are moored could request compliance with the international regulations. For this reason, the international regulations, in general, are easily applicable.

Thus, the International Maritime Organization (IMO) has adopted a relevant role, carrying out prompt actions thereof. So, considering that one of the main ways of reducing greenhouse gas emissions is to reduce carbon fuel consumption on board (it is mostly due to propulsion and electrical generation on board); the outcome is that more efficient use of energy reduces $\mathrm{CO}_{2}$ emissions.

The IMO published the MEPC 203 (62) Resolution, adopted on 15 July 2011, "Amended to the Annex of the Protocol of 1997 to amend the International convention for the prevention of pollution from ships, 1973, as modified by the protocol of 1978 relating thereto" and this resolution has been finally attached to Chapter 4 Annex VI of MARPOL 73/78 Convention, named as "Regulations on Energy Efficiency for Ships".

From the regulatory framework point of view, the resolution adopts two sets of actions:
- Firstly, new ships are submitted to new requirements not applicable to existing ships.

- Secondly, new requirements are dedicated to existing ships that have to be modified to be updated to verify the new regulations, but not in all the extent as to comply with the regulations for new ships because such would bring unfeasible investments. In other cases, a time frame is established to adapt existing vessels or their equipment to the rules.

In our case, air pollution, the new regulation is applicable to vessels over $400 \mathrm{GT}$ and involved in international voyages.

Within this regulation, and taking into account the implementation phase, existing ships are only forced to set out a "Ship Energy Efficiency Management Plan" and to implement it (MARPOL Annex VI, Chapter 4, regulation 22). For new ships, the MARPOL Annex VI, Chapter 4 , rules 20 to 23 apply.

In this rules, MARPOL states the definition of an energy efficiency index. At this moment, this index is mostly applicable to vessels devoted to transport goods or people, whereas it is not yet applicable to "service vessels".

Likewise, MARPOL states that an energy efficiency design index should be calculated, so that it is defined at the design stage taking into account several factors. Additionally, the rules include that an energy efficiency index should be defined, which is the maximum energy efficiency index allowed for the type of ship.

\section{Energy Efficiency Index Definition}

Generally, the energy efficiency design index (EEDI) is defined as the ratio of the environmental impact of the ship and the benefit received by the community from shipping. The IMO, in MEPC Circ1/681, and in the revision MEPC 212(63) on 2 March 2012, provides some guidelines to calculate the EEDI: 


$$
\text { EEDI }=\frac{\text { Impact to enviroment }}{\begin{array}{l}
\text { Benefict to society } \\
\text { (transport work) }
\end{array}}=\frac{\text { Power } \times \text { Fuel Consumption } \times \mathrm{CO}_{2} \text { Emission Factor }}{\text { Capacity } \times \text { Ship Speed }}
$$

And developing the formula:

being:

- $\mathrm{C}_{\mathrm{F}}$ : non-dimensional $\mathrm{CO}_{2}$ emission coefficient. MEi and $\mathrm{AEi}$ stand for main engines and auxiliary engines, respectively.

- $\quad \mathrm{V}_{\text {ref }}$ : Ship speed.

- Capacity: the definition of capacity depending on the type of vessel (GT's, passengers).

- P: Power $(\mathrm{kW})$.

- SFC: Certified specific fuel consumption $(\mathrm{gr} / \mathrm{kWh})$

- $\quad f_{j}$ : is a correction factor to account for the specific design elements. It depends on the ice class and/or the propulsion redundancy

- $\mathrm{f}_{\mathrm{w}}$ : non-dimensional coefficient, indicating the decrease of speed in representative sea conditions of wave height, wave frequency, and wind speed.

- $\mathrm{f}_{\text {eff(i) }}$ : factor of availability of innovative energy efficiency technology.

- $f_{i}$ : factor of technical and/or regulatory constraint as per a table.

\section{Feasible Actions to Increase Energy Efficiency}

Once the EEDI has been defined, we have all the parameters to modify and to perform increased energy efficiency. Thus, we can work with the following parameters:

- Diesel engine power (both propulsion and auxiliary diesel engines); obviously, if the diesel power is reduced, the fuel consumption will be lower. Anyway, we have to take into account the specific fuel consumption curve, because the diesel engine can run in a low power condition and its consumption is very high and the maintenance is also higher if the diesel engine runs in this condition all the time. Therefore, the diesel engines should run at load regimes defined by the manufacturer, or at least very close to this point.

- Capacity: with a higher capacity, the energy efficiency will be lower.

- Speed: if vessel sails at higher speeds, the energy efficient coefficient will be lower, but everybody knows the relation between power and speed follows a cubic law; therefore, in any cases, the power needed to increase the speed a knot, is very high and it is opposed to increased energy efficiency.

Considering the above parameters, it is time to suggest the feasible measures to increase energy efficiency on board. These types of measures will modify the parameters to obtain a better energy efficiency coefficient; these measures can be grouped into three:

- Vessel Design Optimization: the measures regarding hydrodynamic design of the vessel, sizing of the vessel, etc... are included in this item. Therefore, the measures that can be enclosed are the following:

- Choice of vessel size: the unitary cost of the vessel is lower if the vessel is bigger.

- Hydrodynamic optimization of hull: if a good hydrodynamic hull is designed, the power needed to move the vessel to a predetermined speed is lower; hence, fuel consumption is also lower. Obviously, this measure is not applicable to existing vessels, because a large modification should be performed and the high cost of the transformation makes the project not 
viable. On the other hand, this measure is highly recommended for new vessels, when the design can modify the hull to reduce power needs.

- Propeller Optimization; as described in the previous paragraph, hull or propeller optimization in an existing vessel can be an important factor in energy efficiency. As known, the larger the diameter of the propeller the better its efficiency, but the propeller's diameter is limited by the stern height. Additionally, there are several propeller designs whose efficiency is higher than traditionally designed propellers, like CLT design, CR propeller). In this respect, hydrodynamic designers have a vast field to investigate.

- Addition of special devices to steer the water flow; Naval Architects are developing several devices to steer the water flow to the propeller; therefore, the efficiency of the propeller is increasing. Thus, hydrodynamic designers can perform studies on stern shapes.

- Propulsion Optimization: This paragraph mentions the means and devices developed to modify and improve the propulsion system; therefore, the new ways to produce energy (green energies) and their applications in the marine market are also included. Research and development projects are under way such as the following:

- Alternative energy; this way, several technologies, which are applicable on shore installations, can be used on board vessels. A number of initiatives have been studied and developed, as retrofit of conventional vessels to use liquid natural gas as fuel (not LNG vessels), including the passenger vessels. The IMO is involved in developing specific regulations to consider using these types of fuels on board and, nowadays, some vessels have been retrofitted to LNG fuel. The high efficiency of gas achieved 20\% energy saving. Solar panels and wind energy are also applicable.
- Improvements in machinery performance; if the maintenance schedules are verified and the efficiency of the machinery is increased by the designers, finally, energy saving is achieved.

- Reducing energy consumption on board

- Optimizing the ship's operation: if the ship operation can be more efficient, fuel consumption can be lower. The following measures can be enclosed in this item:

- voyage planning optimization;

- Speed optimization; if the vessel can sail at a lower speed and has enough time to arrive to port, fuel consumption is reduced. This measure can be quite interesting for the owner, but sometimes it cannot be applicable (poor environmental conditions, delayed departures and/or arrivals to harbours). Additionally, this measure involves an exhaustive schedule of the vessel and the fleet.

- Trim and ballast optimization; the objective of this measure is that vessel sails under optimal conditions, therefore, minimum resistance and good immersion of the propeller is provided. This measure involves hydrodynamic studies (hull and propeller).

- Hull and propeller maintenance; if hull and propeller are clean, energy saving can achieve 6\%. Nowadays, paint manufacturers are involved in new coatings whereby hull resistance can be optimized by new technology-coating systems.

- Energy management; in this field, the owner can develop procedures and improve modifications on board to increase energy savings. Examples of these measures are: the resistive lights are changed by low consumption lightings or LED lighting technologies, reduction of the load of equipment or deactivating if they are not in use, high maintenance or replacing of the thermal insulation of holds in case of breaking. 


\section{Implementation of Ship Energy Efficiency Management Plans}

Hitherto, we have been talking about the regulations applicable to the energy efficiency on board, and we have explained several measures to take into account to obtain energy savings. We mentioned that MARPOL requires the implementation of a ship energy efficiency management plan (SEEMP) and that it is applicable to all vessels (new and existing ships).

As explained by MARPOL, the purpose of the implementation of the ship energy efficiency management plan is to set out a procedure to be used by the company or the owner and that it will end up in energy saving and reduction of $\mathrm{CO} 2$ emissions.

For this purpose, IMO has developed guidelines to improve ship energy efficiency management plans (Fig. 3.)(See MEPC.1/Circ.683).

The following steps are to be followed in the plan:

- Planning: In this step, a study is to be performed to list the energy use on board and the improvements expected from the application of the energy saving measures; this step studies the measures available and their influence on the vessels.

- Implementation: During this step, the actions applicable to our vessel are chosen, and the procedures to improve the results on board are to be developed.
- Monitoring and Measurements: obviously, when the actions are implemented on board, energy saving will be monitored and it is carried out when we measure fuel consumption and other parameters. In this step, in order to compare energy efficiency, the owner should define an energy efficiency operational indicator (EEOI). The IMO has published guidelines to help the owners in this step (MEPC.1/Circ.684).

- Self-assessment and improvements: after some time, the owner has to evaluate, update, and implement a new energy efficiency plan, or improve the previous plan, taking into account the data obtained in the previous steps and improving the previous plan to implement new measures to increase energy efficiency in the vessel.

SEEMP has to be developed by the owner or technical department, but the main problem found when the owner has started to develop the SEEMP has been the definition of a good energy efficiency operational index. Thus, Bureau Veritas has offered to owners the development of this Ship Energy Efficiency Management Plan, evaluating their needs and defining the EEOI applicable by taking into account the activity of their vessels.

Therefore, the procedure developed by Bureau Veritas has been the following:

- Firstly, during the planning step, Bureau Veritas has offered to owners the full measures available to obtain energy saving on board their

Fig. 3. Guidelines to improve ship energy efficiency management plans

Planning

In this step a study is performed to determinate the use of the energy on board and the improvements to develop.

\section{Implementation}

The applicable measures to our vessel are chosen, and the procedures to improve these measures on board are to be developed.

\section{Monitoring and Measurements}

The energy savings in monitored, in order to compare the energy efficiency, the owner should define an energy efficiency operational indicator (EEOI). 
vessels. From a technical point of view, Bureau Veritas assigns a value (from 1 to 5 ) to each measure, in accordance with the percentage of energy saving expected to be obtained if the measure is implemented on board the vessel. In this point, the owner, depending on the feasibility of the measure (where technical and economic reasons participate) assigns a value to each measure. The final idea is to obtain a value for each measure in function of energy saving and the feasibility to implement the measure on board; therefore, all measures are classified by a value. Throughout the process, communication between the owner and the Bureau Veritas experts is ongoing and due to this good communication between both parts, the planning steps are performed in a short time.

- When the measures are evaluated, the implementation step is easily settled because the only item pending is the implementation of a timeline for each measure by the owner.

- The monitoring step, as indicated, is the most problematic phase because an EEIO index should be defined for each vessel. As stated, this EEIO index is defined by IMO guidelines, but it is only applicable if the vessels transport goods from a port to another port. The problem is when the EEOI index defined by the IMO is used in "working vessels" (fishing vessels, auxiliary vessels, tugboats, fire fighting vessels, vessels to supply fuel to other vessels, ...). In this case, quite a few problems have emerged that have required bigger efforts.

The steps to follow to define new EEOI's applicable to the "working vessels" have been taken according to IMO guidelines. As defined by the IMO guidelines, the EEOI can be defined as:

$$
E E O I=\frac{\sum_{j} F C_{j} x C_{F_{j}}}{\operatorname{cargo} \times D}\left[\frac{\operatorname{TnCO}}{\operatorname{Tn} \times \text { knot }}\right]
$$

Therefore, IMO establishes the EEOI as a measure according to $\mathrm{CO}_{2}$ emissions $\left(\mathrm{Tn} \mathrm{CO}_{2}\right.$ ) for each unit of cargo ( $\mathrm{Tn}$ ) and distance to transport.
As mentioned, this formula cannot be easily applied to working vessels; therefore, Bureau Veritas, in agreement with the owners, has defined several indications to be applicable to the vessels and taking into consideration the parameters that are easily measured on board.

\section{Conclusions}

This procedure has been implemented to several types of vessels like: fishing vessels, tuna fishing vessels, auxiliary vessels, tugboats, fire fighting vessels, vessels used to deliver fuel to other vessels). The experience of carrying out this interaction between the shipyard and Bureau Veritas has given way to a more personal relationship between the Classification Society and the shipyard, a relationship Bureau Veritas seeks to always maintain with all its clients (not only the shipyards), as well as to technical enrichment by both parties.

\section{Bibliography}

http://www.bureauveritas.com/ 